\section{Prevalence and correlates of alcohol use disorders among bipolar patients at Amanuel Mental Specialized Hospital, Addis Ababa (Ethiopia): A cross-sectional institution based study}

Debebe W. Tensae, ${ }^{1}$ Haddis Solomon, ${ }^{1}$ Berhanu Boru, ${ }^{2}$ Wondale Getinet ${ }^{3}$

${ }^{1}$ Amanuel Mental Specialized Hospital, Addis Ababa; ${ }^{2}$ Department of Nursing, College of Medicine and Health

Sciences,University of Gondar;

${ }^{3}$ Department of Psychiatry, College of Medicine and Health Science, University of Gondar, Gondar, Ethiopia

\section{Abstract}

At this time, alcohol use is increasing in African countries. The prevalence of alcohol use disorders (AUDs) remains unknown in patients with psychiatric disorders. This study aimed to assess the prevalence of AUDs among individuals with bipolar disorder in the outpatient department at Amanuel Mental Specialized Hospital. An institution-based cross sectional study was conducted among 412 bipolar patients attending the outpatient department at Amanuel Mental Specialized Hospital from May - July 2015.Participants were selected using a systematic random sampling technique. Semi-structured questionnaires were used to collect socio-demographic and clinical data. Alcohol use disorder was measured using the Alcohol Use Disorders Identification Test (AUDIT-10). Binary logistic regression analysis was performed. The prevalence of alcohol use disorder was found to be $24.5 \%$. Those affected were predominantly female (58.5\%). Being 18-29 years of age $(\mathrm{AOR}=3.86$, 95\% CI: 1.34 , $11.29)$, being $30-44$ years of age $(\mathrm{AOR}=4.99,95 \% \mathrm{CI}: 1.85,13.46)$, being unable to read and write $(\mathrm{AOR}=5.58$, $95 \% \mathrm{CI}: 2.026,13.650)$, having a secondary education $(\mathrm{AOR}=3.198,95 \% \mathrm{CI}$ : 1.149 , $8.906)$, being a farmer $(\mathrm{AOR}=4.54,95 \% \mathrm{CI}$ : $1.67,12.32)$, being employed by the government $(\mathrm{AOR}=3.53,95 \% \mathrm{CI}: 1.36,4.15)$, being a day labourer $(\mathrm{AOR}=3.5,95 \% \mathrm{CI}$ : $1.14,10.77)$, use of other substances during past 12 months $(\mathrm{AOR}=2.06,95 \% \mathrm{CI}$ : 1.06 , 3.99), having a family history of alcohol use $(\mathrm{AOR}=2.18,95 \% \mathrm{CI}: 1.29,3.68)$, having discontinued medication $(\mathrm{AOR}=2.78$, 95\% $\mathrm{CI}: \quad 1.52, \quad 5.07)$, having suicidal thoughts $(\mathrm{AOR}=4.56,95 \% \mathrm{CI}: 2.43,8.54)$, and having attempted suicide $(\mathrm{AOR}=5.67$, $95 \%$ CI: $3.27,9.81$ ) were statistically significant to alcohol use disorder using multivariate logistic analysis. The prevalence of co-morbid alcohol use disorder was high. This finding suggests that screening for risky alcohol use should be integrated into routine hospital outpatient care. Further, preventive measures against alcohol use disorder should be established.

\section{Introduction}

Bipolar disorder (BD) and alcohol use disorder (AUD) are independently a common cause of significant psychopathology in the general population. Co-morbidity of AUD in BD can reach $45 \% .{ }^{1}$ Globally BD affects approximately $1 \%$ of the population and a leading worldwide cause of disability, morbidity and mortality. ${ }^{2-4}$ Bipolar disorder and alcohol use disorders are among the top ten causes of disability due to health-related conditions in all countries, as well as in Low and middle income countries, represent a total of $19.1 \%$ of all disability related to health conditions. ${ }^{5}$ Alcohol consumption is an important contributor to the global burden of disease, responsible for $4 \%$ of disability-adjusted life years and $3.2 \%$ of deaths; problematic alcohol use is associated with economic disadvantage in both resource rich and resource poor countries. .,7 $^{6}$

Epidemiological studies have identified point prevalence for alcohol disorders in the general population of $3 \%$ to $12 \%{ }^{8}$ Alcohol use disorder including both abuse and dependence, are estimated to affect between $13.5 \%$ and $30.3 \%$ of the adult US population and Bipolar disorder is commonly associated with alcohol use disorder $56 \%$ of bipolar patients. ${ }^{9,10}$ Bipolar patients were found to be over six times more likely than the general population to suffer from alcohol or other psychoactive disorders. ${ }^{11}$ Similarly, bipolar disorder also the most common non-substance related Axis I condition in patients with alcohol or substance use disorders. ${ }^{12}$ Several studies reported an association between alcoholism and mood disorder, bipolar disorder represents a significant public health problem, which often goes undiagnosed and untreated for lengthy periods ${ }^{13,14}$ Alcohol is the substance most often abused by bipolar disorder patients, followed by cannabis, amphetamines, and cocaine. ${ }^{15}$ Moderate alcohol consumption in bipolar disorder is associated with more severe manic symptoms compared to abstinence and to poorer social and familial adjustment and increased health care use. ${ }^{16}$

So far, co morbidity is associated with higher rates of specific negative outcomes
Correspondence: Wondale Getinet, Department of Psychiatry, College of Medicine and Health Science, University of Gondar, Gondar, Ethiopia.

Tel.: +251918786780 .

E-mail: wondale22@gmail.com

Key words: Alcohol use, Alcohol use disorders, Bipolar disorder, Co-morbidity.

Acknowledgements: Authors'gratitude goes to the University of Gondar and Amanuel Mental Specialized Hospital, Research and Community Service Core Process for financial support. Funder had no role in study design, data collection, analysis and decision to publish. The corresponding author had full access to all the data in the study and had final responsibility for the decision to prepare the manuscript and submit for publication. Second we would like to thank the study subjects for their willingness to participate in the study. Last but not least our heartfelt thank goes to the supervisors and data collectors for their admirable endeavor during the data collection.

Contributions: DW carried out the manuscript from its conception, analysis and interpretation of data and drafted the manuscript. WG participated in the data analysis and interpretation of data, commented and drafted the manuscript for publication. HS participated in data analysis and review of the manuscript. $\mathrm{BB}$ participated in data analysis and review of the manuscript. All authors read and approved the final manuscript.

Conflict of interest: the authors declare no potential conflict of interest.

Funding: none.

Received for publication: 3 December 2017. Revision received: 14 June 2018.

Accepted for publication: 5 July 2018 .

This work is licensed under a Creative Commons Attribution NonCommercial 4.0 License (CC BY-NC 4.0).

(C) Copyright D.W. Tensae et al., 2018

Licensee PAGEPress, Italy

Journal of Public Health in Africa 2018; 9:829 doi:10.4081/jphia.2018.829

which can complicate diagnosis and treatment, ${ }^{17}$ severe financial problems from poor money management, unstable housing and homelessness, medication noncompliance, relapse (more frequent mood episodes) and re hospitalization, higher treatment costs; violence, legal problems, and incarceration; medical co morbidity, depression and suicide; family burden and high rates of sexually transmitted diseases. ${ }^{18}$ In addition to this, mental disorders 
and their symptoms are risk factors for AUDs and problematic alcohol use is associated with the risk of serious consequences such as cardiovascular disease, unintentional injuries and AUDs. ${ }^{19,20}$

However, people with bipolar disorder are most commonly use alcohol other than other psychoactive substance. The reason is because of their reckless behavior of the illness and they use as symptom relief when they are in a depressive episode. Alcohol use is also may be involved in precipitating an episode of illness and so on. Despite all this there is a lack of published studies conducted in assessing the prevalence of alcohol use disorders among patients who has been diagnosed bipolar disorder in Ethiopia. Thus the aim of this study was to assess the prevalence and factors associated with alcohol use disorder among bipolar patients.

\section{Materials and Methods}

\section{Study area, period and population}

An institution based cross-sectional study design was used. The study was conducted from May-July 2015 at Amanuel Mental Specialized Hospital (AMSH). AMSH was established in 1930 and is situated in Addis Ababa, the capital city of Ethiopia. It is the only mental health hospital in the country. The hospital has a total of 300 beds of which 277 are for inpatients and 23 are Emergency beds. There is also a large outpatient service, with around 115,000 visiting the outpatients department each year.

The participants of this study were individuals with bipolar disorder receiving follow-up care at the outpatient department of Amanuel Mental Health Specialized Hospital which was diagnosed with DSMIV. Single population proportion formula (with the assumption of 5\% margin of error, $95 \%$ confidence level and $50 \%$ proportion) was used to calculate sample size; and it was found to be 423 (including 10\% non response rate). The total number of patients who visited the hospital for the last 12 months were taken from patient records and then the average number of patients per day calculated. Participants were selected by systematic random sampling technique. The study was initially approved by the ethical review board of the University of Gondar and Amanuel Mental Specialized Hospital. Written informed consent was sought for each participant who voluntary and fulfilled the inclusion criteria. All individuals with a clinical diagnosis of bipolar disorder coming for follow up with an age greater than or equal to 18 years were included. Individuals with bipolar disorder who were unable to speak, hear and have no insight were excluded from the study.

\section{Instrument}

A structured questionnaire was employed to collect socio-demographic characteristics and clinical information. For the assessment of alcohol use disorder in bipolar patients Alcohol Use Disorder Identification Test (AUDIT) is used. The AUDIT is a 10 item screening instrument developed by WHO collaborative study conducted in six countries: Australia, Kenya, Bulgaria, Norway, Mexico and the USA. It is designed to screen for a range of drinking problems and in particular for hazardous and harmful consumption. ${ }^{21}$ The AUDIT has been used in a variety of international community and primary health care setting, including many Africa countries. This 10 item questionnaire is brief, easily administered, and is highly reliable and valid in bipolar disorder. ${ }^{22}$ The data collection tool used to evaluate the AUDs; 10 item questions from AUDIT. Items are scored $0-4$, giving a total range between 0 (no problems) and 40 (severe problems) and the items covers three domains; excessive alcohol intake, dependence and problems related to drinking. Study of the utility of the AUDIT in people with Bipolar disorder, reported that a cut off score of 8 or more produced the highest level of correct classification $(89 \%)$ estimated by the composite international diagnostic interview (CIDI) for current alcohol use disorder, with sensitivity of $80 \%$ and specificity of $86 \% .^{21}$

The questionnaires were translated into Amharic (local language) by an Amharic speaking linguist. The back translation was performed by mental health specialist in English and then a consensus version was developed in a group discussion by involving the research team. This was compared with the original version, and confirmed to be satisfactory for use. The questionnaires were tested on $5 \%$ sample patients to make it easier for the participants to understand and complete. AUDIT score of 1-7 social drinking, 8-15 "hazardous drinking", 16-19 "harmful drinking" and a score of 20 or above probable alcohol dependence. ${ }^{23}$ Social support was measured using Oslo Social Support scale: Has social support: Scoring of 9-14 during Oslo-3 Social Support Scale (OSS-3). Has no social support: Scoring of 3-8 using Oslo-3 Social Support Scale (OSS-3). In addition, we asked one question in the presence of medical illness with bipolar patients.

\section{Ethics approval and consent to par- ticipate}

The study proposal was initially approved by the ethical review board of the University of Gondar and Amanuel Mental Specialized Hospital. A formal letter of permission obtained, we submitted to the respective outpatient department. The information about the study was given to the participants. Written informed consent was sought for each participant who voluntary and fulfilled the inclusion criteria. Only anonymous data collected in private rooms.

\section{Data collection and analysis}

Data were collected by face-to-face interview using pretested, structured questionnaire with the Amharic version of the source-demographic, clinical factors, and AUDIT questionnaires. EPI info version 3.5.3 statistical software and SPSS windows version 20 program were used for analysis. Descriptive statistics (frequencies, tables, percentages, means and standard deviation) were used for the socio demographic and clinical variables, including individual's response AUDIT. Binary logistic regression and odds ratio with $95 \%$ confidence interval were used to identify the independently associated factors with alcohol use disorder. Statistical significance was accepted at the $5 \%$ level $(\mathrm{P}<0.05)$.

\section{Results}

A total of 412 participants participated in this study with a $97 \%$ response rate.

\section{Socio demographics' and clinical characteristics of participants}

The majority of the participants were women $241(58.5 \%)$. Among the participants, $42.2 \%$ were in the age range of $30-$ 44. Concerning educational status 141 $(34.2 \%)$ were secondary education, 218 $(60.2 \%)$ were Orthodox in religion and 128 $(31.1 \%)$ were Divorced. One hundred and thirty-six $(33 \%)$ of the participants were Amhara by Ethnicity. Out of 412 participants, $126(30.6 \%)$ were jobless and 364 $(88.3 \%)$ were living with family (Table 1$)$.

\section{Factors associated with alcohol use disorder}

During bivariate analysis variables like sex, age groups, educational levels, occupation, and use of other substances other than alcohol in the past 12 months, family history of alcohol use, medication discontinuation, suicidal thought and suicidal attempt were factors associated with alcohol use disorder. On the other point of view marital status, shelter, social support, duration of mental illness, hospitalization was not associated with alcohol use disorders and 
excluded from further analysis. From the multivariate analysis; age groups 18-29 $(\mathrm{AOR}=3.86, \mathrm{CI}: 1.34,11.29)$, age group 30 44 (AOR=4.99, CI: 1.85, 13.46), divorced and widowed $(\mathrm{AOR}=0.06, \mathrm{CI}: 0.01,0.35)$ educational status: unable to read and write $(\mathrm{AOR}=5.25$, CI: 2.02, 13.65), secondary education $(\mathrm{AOR}=3.19$, CI: 1.14, 8.90), occupation: government employed $(\mathrm{AOR}=3.53$, CI: 1.36, 4.15), farmer $(\mathrm{AOR}=4.54, \mathrm{CI}: 1.67,12.32)$, daily laborer $(\mathrm{AOR}=3.5$, CI: 1.14, 10.72), Other substances in the past 12 months ( $\mathrm{AOR}=2.06$, CI 1.06,3.99), family history of alcohol use (AOR=2.18, CI: 1.29,3.68), medication discontinuation $(\mathrm{AOR}=2.78, \mathrm{CI}$ : 1.52, 5.07), Suicidal thought ( $\mathrm{AOR}=4.56, \mathrm{CI}: \quad 2.43, \quad 8.54)$, suicidal attempt (AOR=5.67, CI: 3.27, 9.81) were factors statistically significant with alcohol use disorder at $\mathrm{P}$-value $<0.05$ (Table 2).

\section{Discussion}

The aim of this study was to assess the prevalence and associated factors of alcohol use disorder among patients with bipolar disorder at Amanuel Mental Specialized Hospital. In this study, the prevalence of alcohol use disorder was $24.5 \%$. This result $(24.5 \%)$ is lower than the study carried out in South Africa 34.8\%, ${ }^{24}$ in USA 44.7\%, ${ }^{25}$ Epidemiological catchment area study in USA $46.2 \%{ }^{26}$ This variation may be due to using different diagnostic criteria or different rating scales in diagnosing alcohol use disorders, its geographical situation, cultural setting, economic status and population being studied, the study design, study period and the assessment of tools used.

In contrast, it is higher than the study done in Borana Ethiopia 1.6\%,27 Tanzania $5.7 \%,{ }^{28}$ Brazil $18.4 \% .29$ The possible explanations for the variation may be due to use of different tools, use of different cutoff points, geographical areas and cultures of the study subject study done in Tanzania at urban population, study in south Brazil also on general population which may lower the prevalence of alcohol use disorder, In Ethiopia this high prevalence difference it may be due to the availability of homemade brewed alcohol like Tej, Arakie and Tella were easily accessible with the cost patients could afford and co morbidity in bipolar patients is more common.

Regarding the associated factors, there was a statistically significant association between age groups 18-29 years were more than three times $(\mathrm{AOR}=3.8,95 \% \mathrm{CI}$ : $1.34,11.29)$ and $30-44$ years and four times (AOR=4.9, 95\%CI: $1.85,13.46)$ odds of alcohol use disorder as compared to those
Table 1. Distribution of participants by their socio-demographic and clinical characteristics at Amanuel Mental Specialized Hospital, $2015(\mathrm{n}=412)$.

\begin{tabular}{|c|c|c|}
\hline Variable & Number & $\%$ \\
\hline $\begin{array}{l}\text { Age } \\
\quad 18-29 \\
30-44 \\
\geq 45\end{array}$ & $\begin{array}{l}159 \\
174 \\
79\end{array}$ & $\begin{array}{l}38.6 \\
42.2 \\
19.2\end{array}$ \\
\hline $\begin{array}{l}\text { Sex } \\
\text { Male } \\
\text { Female }\end{array}$ & $\begin{array}{l}171 \\
241\end{array}$ & $\begin{array}{l}41.5 \\
58.5\end{array}$ \\
\hline $\begin{array}{l}\text { Marital status } \\
\text { Single } \\
\text { Married } \\
\text { Separated } \\
\text { Divorced } \\
\text { Widowed }\end{array}$ & $\begin{array}{c}12 \\
17 \\
35 \\
120 \\
220\end{array}$ & $\begin{array}{r}2.9 \\
4.1 \\
8.5 \\
31.1 \\
53.4\end{array}$ \\
\hline $\begin{array}{l}\text { Religion } \\
\text { Orthodox } \\
\text { Muslim } \\
\text { Protestant } \\
\text { Catholic } \\
\text { Others } \\
\end{array}$ & $\begin{array}{l}218 \\
105 \\
54 \\
12 \\
13\end{array}$ & $\begin{array}{l}52.9 \\
25.5 \\
13.1 \\
2.9 \\
5.6\end{array}$ \\
\hline $\begin{array}{l}\text { Ethnicity } \\
\text { Amhara } \\
\text { Oromo } \\
\text { Tigre } \\
\text { Gurage } \\
\text { Others }\end{array}$ & $\begin{array}{l}136 \\
131 \\
92 \\
21 \\
32\end{array}$ & $\begin{array}{c}33.0 \\
31.8 \\
22.3 \\
5.1 \\
7.8\end{array}$ \\
\hline $\begin{array}{l}\text { Educational status } \\
\text { Unable read \&write } \\
\text { Primary } \\
\text { Secondary } \\
\text { Diploma \& above }\end{array}$ & $\begin{array}{c}51 \\
148 \\
141 \\
72\end{array}$ & $\begin{array}{l}12.4 \\
35.9 \\
34.2 \\
17.5\end{array}$ \\
\hline $\begin{array}{l}\text { Job/occupation } \\
\text { Government employed } \\
\text { Merchant } \\
\text { Student } \\
\text { Farmer } \\
\text { Day Labor } \\
\text { Housewife } \\
\text { Jobless }\end{array}$ & $\begin{array}{l}63 \\
51 \\
42 \\
36 \\
28 \\
66 \\
126\end{array}$ & $\begin{array}{r}15.3 \\
12.4 \\
10.2 \\
8.7 \\
6.8 \\
16.0 \\
30.6\end{array}$ \\
\hline $\begin{array}{l}\text { Income } \\
\quad \leq 400 \\
401-700 \\
701-1200 \\
\geq 1201\end{array}$ & $\begin{array}{l}171 \\
39 \\
117 \\
85\end{array}$ & $\begin{array}{r}41.5 \\
9.5 \\
41.5 \\
20.6\end{array}$ \\
\hline $\begin{array}{l}\text { Living circumstance } \\
\text { With family } \\
\text { Alone } \\
\text { Others }\end{array}$ & $\begin{array}{c}364 \\
43 \\
5\end{array}$ & $\begin{array}{c}88.3 \\
10.4 \\
1.2\end{array}$ \\
\hline $\begin{array}{l}\text { Shelter } \\
\text { Yes, I do have } \\
\text { Now I am homeless }\end{array}$ & $\begin{array}{l}310 \\
102 \\
\end{array}$ & $\begin{array}{l}75.2 \\
24.8 \\
\end{array}$ \\
\hline $\begin{array}{l}\text { Substance use In the past } 12 \\
\text { Yes } \\
\text { No }\end{array}$ & $\begin{array}{c}319 \\
93\end{array}$ & $\begin{array}{l}77.5 \\
22.5\end{array}$ \\
\hline $\begin{array}{l}\text { Family history of alcohol use } \\
\text { Yes } \\
\text { No }\end{array}$ & $\begin{array}{l}156 \\
256 \\
\end{array}$ & $\begin{array}{l}37.8 \\
62.2\end{array}$ \\
\hline $\begin{array}{l}\text { Medication Discontinuation } \\
\text { Yes } \\
\text { No }\end{array}$ & $\begin{array}{l}147 \\
265\end{array}$ & $\begin{array}{l}35.6 \\
64.4\end{array}$ \\
\hline $\begin{array}{l}\text { Previous Hospitalization } \\
\text { Yes } \\
\text { No }\end{array}$ & $\begin{array}{l}100 \\
312\end{array}$ & $\begin{array}{l}24.3 \\
75.7\end{array}$ \\
\hline $\begin{array}{l}\text { Suicidal thought } \\
\text { Yes } \\
\text { No }\end{array}$ & $\begin{array}{l}102 \\
309\end{array}$ & $\begin{array}{l}25 \\
75\end{array}$ \\
\hline $\begin{array}{l}\text { Suicidal attempt } \\
\text { Yes } \\
\text { No }\end{array}$ & $\begin{array}{l}102 \\
310\end{array}$ & $\begin{array}{l}24.7 \\
75.3\end{array}$ \\
\hline
\end{tabular}


patients who were on age group $\geq 45$ years of age. These results were consistent with the previous study done in USA. ${ }^{2}$ Possible reasons in bipolar disorder the onset of illness early 20's and above, by nature the reckless behavior leads to expose to use alcohol and their use as symptom relief when they are in depression episode, and their psychological problem and alcohol use also may involved in precipitated an episode of illness might be the reason.

Those patients with occupational status being farmer four times $(\mathrm{AOR}=4.54$, 95\%CI: 1.67,12.32) odds of alcohol use disorder as compared to unemployed.
Government employed $(\mathrm{AOR}=3.5,95 \% \mathrm{CI}$ : $1.36,4.15)$ and daily laborer $(\mathrm{AOR}=3.5$, 95\%CI: $1.14,10.72$ ) were more than three and four times odds of alcohol use disorder as compared to unemployed and this finding consistent with other literature. ${ }^{18}$ This may be due to the fact that those individuals who have income (who have got money) may bought alcohol easily, and enjoy themselves by taking it.

Those patients who cannot read and write had more than five times $(\mathrm{AOR}=5.25$, $95 \%$ CI: 2.02, 13.65) odds of having alcohol use disorder as compared to diploma and above participants even though literature associated with those who have lower educational level. ${ }^{15}$ Because they don't have awareness about harm full consequences of alcohol in spite of their educational background.

Those who used other substances in the past twelve months other than alcohol were two times more likely $(\mathrm{AOR}=2,95 \% \mathrm{CI}$ : 1.06-3.99) odds of having alcohol use disorder as compared to no other substances use in the past 12 months. ${ }^{13}$ This is due to the impulsiveness of the bipolar disorder by itself in addition to alcohol use.

Those patients who have family history of alcohol use were two times more likely

Table 2. Factors associated with Alcohol use disorder (bivariate and multivariate) analysis, at AMSH, 2015.

\begin{tabular}{|c|c|c|c|c|}
\hline Explanatory variables & $\begin{array}{l}\text { Alcohol use disorder, } \\
\text { Yes (\%) / No (\%) }\end{array}$ & COR $(95 \% \mathrm{CI})$ & AOR $(95 \% \mathrm{CI})$ & P value \\
\hline \multicolumn{5}{|l|}{ Age } \\
\hline $18-29$ & $60(37.2) / 101(62.8)$ & $3.36(0.90,4.12)$ & $3.86(1.34,11.29)$ & $0.012^{* *}$ \\
\hline $30-44$ & $29(16.9) / 142(83.1)$ & $1.16(1.71,7.47)$ & $4.99(1.85,13.46)$ & $0.001^{* * *}$ \\
\hline$\geq 45$ & $12(15) / 68(85)$ & 1 & 1 & \\
\hline $\begin{array}{l}\text { Sex } \\
\text { Male } \\
\text { Female }\end{array}$ & $\begin{array}{c}55(32.1) / 116(67.9) \\
46(19) / 195(81)\end{array}$ & $\begin{array}{c}2(1.27,3.16) \\
1\end{array}$ & $\begin{array}{c}0.8(0.43,1.50) \\
1\end{array}$ & 0.50 \\
\hline \multicolumn{5}{|l|}{ Marital status } \\
\hline Married & $8(66.6) / 4(33.4)$ & 1 & 1 & 0.73 \\
\hline Single & $14(87.5) / 2(12.5)$ & $0.3(0.62,23.55)$ & $0.66(0.64,6.90)$ & $0.002 *$ \\
\hline Divorced \& Widowed & $79(20.5) / 305(79.5)$ & $7.7(0.03,0.44)$ & $0.06(0.01,0.35)$ & \\
\hline $\begin{array}{l}\text { Educational status } \\
\text { Unable read \&write } \\
\text { Primary } \\
\text { Secondary } \\
\text { Diploma \& above }\end{array}$ & $\begin{array}{c}11(21.5) / 40(78.5) \\
38(25.6) / 110(74.4) \\
35(24.8) / 106(75.2) \\
17(23.6) / 55(76.4)\end{array}$ & $\begin{array}{c}0.9(1.84,11.07) \\
1.12(1.09,5.32) \\
1.06(1.00,4.94) \\
1\end{array}$ & $\begin{array}{c}5.25(2.02,13.65) \\
4.18(1.46,12.00) \\
3.19(1.14,8.90) \\
1\end{array}$ & $\begin{array}{c}0.001 * * * \\
0.008^{*} \\
0.026^{*}\end{array}$ \\
\hline $\begin{array}{l}\text { Job/occupation } \\
\text { Government employed } \\
\text { Merchant } \\
\text { Student } \\
\text { Farmer } \\
\text { Day Labor } \\
\text { Housewife } \\
\text { Jobless }\end{array}$ & $\begin{array}{c}14(22.2) / 49(77.8) \\
10(19.6) / 41(80.4) \\
15(35.7) / 27(64.3) \\
12(33.3) / 24(66.7) \\
9(32.1) / 19(67.9) \\
7(10.6) / 59(89.4) \\
34(26.9) / 92(73.1)\end{array}$ & $\begin{array}{c}0.8(1.66,7.12) \\
0.7(1.47,6.95) \\
1.5(2.39,11.71) \\
1.35(2.04,10.61) \\
1.3(1.41,8.99) \\
0.3(1.23,3.2) \\
1\end{array}$ & $\begin{array}{c}3.53(1.36,4.15) \\
2.01(0.75,5.42) \\
2.39(0.85,6.71) \\
4.54(1.67,12.32) \\
3.50(1.14,10.72) \\
4(5.21,7.23) \\
1\end{array}$ & $\begin{array}{c}0.009 * \\
0.164 \\
0.099 \\
0.003^{*} \\
0.028 * \\
0.997\end{array}$ \\
\hline $\begin{array}{l}\text { Social support } \\
\text { High social support (9-14) } \\
\text { Low social support (3-8) }\end{array}$ & $\begin{array}{l}77(25.3) / 227(74.7) \\
24(22.2) / 84(77.8)\end{array}$ & $\begin{array}{c}1.2(0.70,2.00) \\
1\end{array}$ & $\begin{array}{c}3(4.3,8.32) \\
1\end{array}$ & 0.519 \\
\hline \multicolumn{5}{|c|}{ Substance use in the past 12 months } \\
\hline $\begin{array}{l}\text { Yes } \\
\text { No }\end{array}$ & $\begin{array}{l}70(21.9) / 249(78.1) \\
31(33.3) / 62(66.7)\end{array}$ & $\begin{array}{c}0.56(1.28,3.49) \\
1\end{array}$ & $\begin{array}{c}2.06(1.06,3.99) \\
1\end{array}$ & $0.032 *$ \\
\hline $\begin{array}{l}\text { Family history of alcohol use } \\
\text { No } \\
\text { Yes }\end{array}$ & $\begin{array}{l}60(23.4) / 196(76.6) \\
41(26.2) / 115(73.8)\end{array}$ & $1.17(1.41,3.51)$ & $2.18(1.29,3.68)$ & $0.001 * * *$ \\
\hline $\begin{array}{l}\text { Medication discontinuation } \\
\text { No } \\
\text { Yes }\end{array}$ & $\begin{array}{c}40(15) / 225(85) \\
61(41.4) / 86(58.6)\end{array}$ & $\begin{array}{c}1 \\
4(2.07,5.26)\end{array}$ & $\begin{array}{c}1 \\
2.78(1.52,5.07)\end{array}$ & $0.001 * * *$ \\
\hline $\begin{array}{l}\text { Suicidal thought } \\
\text { No } \\
\text { Yes }\end{array}$ & $\begin{array}{c}0(0) / 309(100) \\
102(99) / 1(1)\end{array}$ & $\begin{array}{c}1 \\
0.0003(2.75,7.30)\end{array}$ & $\begin{array}{c}1 \\
4.56(2.43,8.54) \\
\end{array}$ & $0.000 * * *$ \\
\hline $\begin{array}{l}\text { Suicidal attempt } \\
\text { No } \\
\text { Yes } \\
\end{array}$ & $\begin{array}{c}7(2.2) / 303(97.8) \\
94(96) / 8(4) \\
\end{array}$ & $0.002(0.001,0.006)$ & $\begin{array}{c}1 \\
5.67(3.27,9.81) \\
\end{array}$ & $0.000^{* * *}$ \\
\hline
\end{tabular}

Note: significant at $\mathrm{P}<0.05^{*}$, significant at $\mathrm{P}<0.01^{* *}$, significant at $\mathrm{P}<0.001^{* * *}$. 
$(\mathrm{AOR}=2.18,95 \% \mathrm{CI}: 1.29,3.68)$ odds of having alcohol use disorder as compared to no family history of alcohol use. ${ }^{11,16}$ This is due to both the bipolar and AUDs have both biological/heredity effect, the overlap between alcohol use problems and other psychiatric problems could indicate similar etiological factors in the development of such problems.

Those patients who had difficulties of adherence to their antipsychotic and mood stabilizer had around two times (AOR=2.78, 95\%CI: 1.52, 5.07) odds of having an alcohol use disorder than adherent individuals. The possible reason may be those patients who had difficulties of adherence to their antipsychotics and mood stabilizer may result in break through relapse that may lead an individual to develop Bipolar disorder leads to alcohol use disorder and have no insight about the consequence of the disease.

Those patients who had suicidal thought and attempt were four and five times $(\mathrm{AOR}=4.56,95 \% \mathrm{CI}: 2.43,8.54)$ and (AOR=5.67 95\%CI: 3.27, 9.81) odds of having alcohol use disorder than those who have no suicidal thought and attempt respectively. ${ }^{10}$ The results of the current study are similar to co-morbidity studies in the developed countries and indicate that individuals with bipolar disorder are significantly more likely to suffer from a range of other psychiatric problems like alcohol use. Overlap between alcohol use problems and other psychiatric problems could indicate similar causative factors in the development of such problems. This is due to the Nature of the disease that during their depressive episode they become hopelessness and worthlessness and the alcohol uses more worsen and becomes suicidal.

\section{Limitations of the study}

This study has some important limitations that should be kept in mind when interpreting the results. First, the cross-sectional nature of the study design does not confirm definitive cause and effect relationship. Second the symptom similarity of bipolar disorder and the effect of alcohol use disorder. In addition, some of the independent variables like suicidal thought, suicide attempt, and duration of illness and family history of alcohol use rely on patient's past history that might have recalled bias. Finally, some variables were assessed with single questions, for example, the difficulties of adherence to their antipsychotic and mood stabilizer that may lead some patients to respond inappropriately.

\section{Conclusions}

Overall, the prevalence of alcohol use disorder was found to be high. Age, educational status, occupational status, family history of alcohol use, Non adherence, Suicidal thought, Suicidal attempt was associated independently with alcohol use disorder in bipolar patients. These findings add important evidence in the existing few studies in Ethiopia and other developing countries on the behavioral aspect of an individual with bipolar disorder. Awareness creation through health education about alcohol use disorder, consequence and its early management, are suggested. Additional researches with qualitative and quantitative study methods are also suggested, in order to explore the relationship of socio-demographic and alcohol use on bipolar disorder.

\section{References}

1. Farren CK, Hill KP, Weiss RD. Bipolar disorder and alcohol use disorder: a review Curr Psychiatr Rep 2012;14: 659-66.

2. Balamurugan E. Bipolar Disorder Boon or a Curse A Comprehensive Review. Int J Pharmaceutic Biol Arch 2014;5.

3. Fekadu A, Shibre T, Alem A, et al. Bipolar disorder among an isolated island community in Ethiopia. J Affect Disord 2004;80:1-10.

4. Beyero T, Alem A, Kebede D, et al. Mental disorders among the Borana semi-nomadic community in Southern Ethiopia. World Psychiatry 2004;3.

5. WHO. Global status report on alcohol Geneva. World Health Organization 2014.

6. Reisdorfer E, Büchele F, Pires ROM, Boing AF. Prevalence and associated factors with alcohol use disorders among adults: a population-based study in southern Brazil. Rev Brasileira Epidemiol 2012;15:582-94.

7. Mbatia J, Jenkins R, Singleton N, White B. Prevalence of alcohol consumption and hazardous drinking, tobacco and drug use in urban Tanzania, and their associated risk factors. Int J Environm Res Publ Health 2009;6:1991-2006.

8. Piterman L, Jones K, Castle D. Bipolar disorder in general practice: challenges and opportunities. Med J Aust 2010; 193:S14-S7.

9. Barros MBdA, Botega NJ, Dalgalarrondo P, et al. Prevalence of alcohol abuse and associated factors in a population-based study. Rev Saúde Pública 2007;41:502-9.

10. Oquendo MA, Currier D, Liu S, et al.
Increased risk for suicidal behavior in comorbid bipolar disorder and alcohol use disorders. J Clin Psychiatry 2010;71.

11. Salloum IM, Thase ME. Impact of substance abuse on the course and treatment of bipolar disorder. Bipolar Disord 2000;2:269-80.

12. Swann AC. Bipolar disorder and substance abuse: two disorders or one? J Dual Diagn 2005;1:9-23.

13. Victor SE, Johnson SL, Gotlib IH. Quality of life and impulsivity in bipolar disorder. Bipolar Disord 2011;13:303-9.

14. Behrendt S, Beesdo-Baum K, Zimmermann $\mathrm{P}$, et al. Role of mental disorders in the risk and speed of transition to alcohol use disorders among community youth. Psychol Med 2011;41:1073-85.

15. Nery FG, Soares JC. Comorbid bipolar disorder and substance abuse:Evidencebased options. Curr Psychiatry 2011;10.

16. Lagerberg TV, Andreassen OA, Ringen PA, et al. Excessive substance use in bipolar disorder is associated with impaired functioning rather than clinical characteristics, a descriptive study. BMC Psychiatry 2010;10.

17. Ostacher MJ, Perlis RH, Nierenberg AA, et al. Impact of substance use disorders on recovery from episodes of depression in bipolar disorder patients: prospective data from the Systematic Treatment Enhancement Program for Bipolar Disorder (STEP-BD). Am J Psychiatry 2009; 167:289-97.

18. Hapangama A, Kuruppuarachchi K, Pathmeswaran A. Substance use disorders among mentally ill patients in a General Hospital in Sri Lanka: prevalence and correlates. Ceylon Med J 2013;58:111-5.

19. Bellivier F, Yon L, Luquiens A, et al. Suicidal attempts in bipolar disorder: results from an observational study (EMBLEM). Bipolar Disord 2011;13:377-86.

20. Bahorik AL, Newhill CE, Eack SM. Characterizing the longitudinal patterns of substance use among individuals diagnosed with serious mental illness after psychiatric hospitalization. Addiction 2013;108:1259-69.

21. Pradhan B, Chappuis F, Baral D, et al. The alcohol use disorders identification test (AUDIT): validation of a Nepali version for the detection of alcohol use disorders and hazardous drinking in medical settings. Subst Abuse Treat Prev Policy 2012;7.

22. Saunders JB, Aasland OG, Babor TF, et al. Development of the alcohol use dis- 
orders identification test (AUDIT): WHO collaborative project on early detection of persons with harmful alcohol consumption $\square$ II. Addiction 1993;88:791-804.

23. Babor TF, Higgins-Biddle JC, Saunders JB, Monteiro MG. AUDIT: The Alcohol Use Disorders Identification Test Guidelines for Use in Primary Care: World Health Organization. Geneva, Switzerland. 2001.

24. Pengpid S, Peltzer K, Heever HVd. Prevalence of alcohol use and associated factors in urban hospital outpatients in South Africa. Int J Environ Res Public Health 2011;8:2629-39.

25. Chengappa KR, Levine J, Gershon S, Kupfer DJ. Lifetime prevalence of substance or alcohol abuse and dependence among subjects with bipolar I and II disorders in a voluntary registry. Bipolar Disord 2000;2:191-5.

26. Sonne SC, Brady KT. Bipolar disorder and alcoholism. Alcohol Res 2002;26.

27. Beyero T, Alem A, Kebede D, et al. Mental disorders among the Borana semi-nomadic community in Southern Ethiopia. World Psychiatry 2004;3.
28. Mbatia J, Jenkins R, Singleton N, White B. Prevalence of alcohol consumption and hazardous drinking, tobacco and drug use in urban Tanzania, and their associated risk factors. Int $\mathrm{J}$ Environ Res Public Health 2009;6:1991-2006.

29. Reisdorfer E, Büchele F, Pires ROM, Boing AF. Prevalence and associated factors with alcohol use disorders among adults: a population-based study in southern Brazil. Rev Brasil Epidemiol 2012;15:582-94. 